University of Nebraska - Lincoln

DigitalCommons@University of Nebraska - Lincoln

\title{
Association of Wild Bird Density and Farm Management Factors with the Prevalence of E. coli 0157 in Dairy Herds in Ohio (2007-2009)
}

\author{
N. Cernicchiaro \\ Kansas State University, ncernic@vet.k-state.edu \\ D. L. Pearl \\ University of Guelph, dpearl@uoguelph.ca \\ S. A. McEwen \\ University of Guelph \\ L. Harpster \\ Ohio State University - Main Campus \\ H. J. Homan \\ United States Department of Agriculture \\ See next page for additional authors \\ Follow this and additional works at: https://digitalcommons.unl.edu/icwdm_usdanwrc \\ Part of the Life Sciences Commons
}

Cernicchiaro, N.; Pearl, D. L.; McEwen, S. A.; Harpster, L.; Homan, H. J.; Linz, G. M.; and LeJeune, J. T., "Association of Wild Bird Density and Farm Management Factors with the Prevalence of E. coli 0157 in Dairy Herds in Ohio (2007-2009)" (2012). USDA National Wildlife Research Center - Staff Publications. 1080.

https://digitalcommons.unl.edu/icwdm_usdanwrc/1080

This Article is brought to you for free and open access by the U.S. Department of Agriculture: Animal and Plant Health Inspection Service at DigitalCommons@University of Nebraska - Lincoln. It has been accepted for inclusion in USDA National Wildlife Research Center - Staff Publications by an authorized administrator of DigitalCommons@University of Nebraska - Lincoln. 


\section{Authors}

N. Cernicchiaro, D. L. Pearl, S. A. McEwen, L. Harpster, H. J. Homan, G. M. Linz, and J. T. LeJeune 


\title{
Association of Wild Bird Density and Farm Management Factors with the Prevalence of E. coli 0157 in Dairy Herds in Ohio (2007-2009)
}

\author{
N. Cernicchiaro' ${ }^{1}$, D. L. Pearl' ${ }^{2}$, S. A. McEwen², L. Harpster ${ }^{3}$, H. J. Homan ${ }^{4}$, G. M. Linz ${ }^{4}$ and J. T. LeJeune ${ }^{3}$ \\ 1 Department of Diagnostic Medicine/Pathobiology, College of Veterinary Medicine, Kansas State University, Manhattan, KS, USA \\ 2 Department of Population Medicine, Ontario Veterinary College, University of Guelph, Guelph, ON, Canada \\ ${ }^{3}$ Food Animal and Health Research Program, Ohio Agricultural Research and Development Center, The Ohio State University, Wooster, OH, USA \\ ${ }^{4}$ United States Department of Agriculture, National Wildlife Research Center, Great Plains Field Station, Bismarck, ND, USA
}

\section{Impacts}

- Wild birds harbour foodborne pathogens; however, the extent to which birds contribute to the epidemiology of these pathogens in cattle is unknown.

- Results from recent studies support the hypothesis that birds, in particular starlings, play a crucial role in the dissemination of foodborne bacteria among dairy farms.

- More research is needed to define the specific role of starlings on the epidemiology and transmission of Escherichia coli O157:H7 among dairy farms.

\section{Keywords:}

E. coli 0157; Sturnus vulgaris; starlings; birds; cattle; epidemiology

\section{Correspondence:}

N. Cernicchiaro. Department of Diagnostic Medicine/Pathobiology, College of Veterinary Medicine, Kansas State University, Mosier Hall J118, 1800 Denison Ave, Manhattan, KS 66506-5606, USA. Tel.: (785) 532 2895; Fax: (785) 532 4039; E-mail: ncernic@vet. k-state.edu

Received for publication May 16, 2011

doi: 10.1111/j.1863-2378.2012.01457.x

\section{Summary}

Our objective was to determine the role that European starlings (Sturnus vulgaris) play in the epidemiology of Escherichia coli O157:H7 in dairy cattle. We visited 150 dairy farms in Ohio twice during summer and fall months from 2007 to 2009. Fresh faecal pats from 30 lactating cows were collected during each visit. Information on farm management and environmental variables was gathered through a questionnaire administered to the farm owner. The number of starlings observed on the farm was also recorded. Approximately $1 \%$ of dairy cattle and $24 \%$ of farms were positive for E. coli O157. Risk factors associated with the presence of E. coli O157 in faecal pats included contact between adult cattle and calves, types or number of ventilation and manure management systems and number of birds per milking cow.

\section{Introduction}

European starlings (Sturnus vulgaris) often congregate by the thousands at Concentrated Animal Feeding Operations in the United States (Linz et al., 2007). These birds are considered nuisance pests because they eat large amounts of livestock feed and contaminate the farm environment with excrement (Pimentel et al., 1999). Moreover, these birds are aggressive and often displace native species of birds. European starlings (henceforth starlings) cause at least $\$ 800$ million in agricultural damage in the USA, annually (Pimentel et al., 1999, 2005). If we add the public health costs associated with the potential starlings have of being vectors in transmission of foodborne bacteria, the resulting economic impact of this species could be even greater. Wild birds indeed harbour foodborne pathogens, such as Escherichia coli O157:H7 (E. coli O157), Salmonella spp., Campylobacter jejuni and Listeria spp; however, the extent to which birds contribute to the epidemiology of foodborne pathogens in cattle is unknown (Luechtefeld et al., 1980; Fenlon, 1985; Quessy and Messier, 1992; Pimentel et al., 1999, 2005; Daniels et al., 2003).

Results from recent studies support the hypothesis that birds, in particular starlings, play a crucial role in 
dissemination of foodborne bacteria among dairy farms (Wetzel and LeJeune, 2006; LeJeune et al., 2008). LeJeune et al. (2008) study, conducted on five dairy farms in Ohio, showed that $2.2 \%$ of starlings and $2.6 \%$ of cattle were positive for E. coli O157 (LeJeune et al., 2008). In addition, starlings captured and radio tagged at five farms (and at surrounding dairy farms) indicated strong site fidelity, with many of the radio-tagged birds returning daily to the same farm from late summer through early fall (Homan, 2011). Moreover, indistinguishable restriction endonuclease digestion profiles (REDPs) of E. coli O157 were isolated from wild bird excreta collected in two geographically distant (32.5 km apart) dairy farms on the same sampling date (Van Donkersgoed et al., 2001; Wetzel and LeJeune, 2006). This suggests that wild birds may be transmission vectors in dissemination of E. coli O157. These results have led us to hypothesize that farms with large numbers of starlings will have greater E. coli O157 prevalence than farms with low numbers of starlings. Our study's objectives were to determine whether the prevalence of E. coli O157 in dairy cattle was associated with (i) the presence of on-farm populations of starlings, (ii) differences in farm management practices and (iii) on-site environmental variables.

\section{Materials and Methods}

\section{Sample size estimation}

This study was not intended to determine the prevalence of E. coli O157 in our study population but the effect of risk factors associated with the occurrence of E. coli O157 in cattle faecal samples. Thus, the determination of the number of farms and the number of samples per farm was based on the hierarchical structure of the data (Dohoo et al., 2009). Our sample size was estimated based on the assumptions of E. coli O157 prevalence in the study area, a tendency towards clustering of E. coli O157 status among samples on farms and our intention to statistically detect differences in the prevalence of $8 \%$ and $4 \%$ between farms with and without bird infestations, respectively. Recognizing the impact of auto-correlation among samples from the same farms, we assumed an intra-class correlation coefficient (ICC) of $8 \%$ in our sample size calculation. Assuming a type I error of $5 \%$, and the above prevalence and ICC estimates, 150 farms with 30 faecal pat samples per herd were estimated to provide $>80 \%$ power to detect a significant difference between groups.

\section{Farm recruitment}

Dairy farms were selected from the Ohio Commercial Grade A listing of producers. Farms were recruited from counties of higher dairy cattle density, to minimize travel time and expense. Farmers were contacted by telephone requesting their participation in the study, and based on their willingness to participate were recruited until the required sample size was obtained. Criteria for participation included a minimum of 30 lactating cows and willingness to complete a questionnaire on farm management practices. The recruited farms were from 32 counties in northern Ohio, USA. The period of recruitment of farms to participate in the study began in June 2007 and continued until all farms $(n=150)$ were enrolled (September 2009).

A repeated cross-sectional design was employed. Each farm was visited twice, with an average of 88 days between visits (range $=35-454$ days), with the exceptions of one farm that was visited once and another farm that was visited on three occasions. These visits took place during the summer and fall months of 2007-2009 with the timing of sampling as follows: 31 farms were sampled in 2007 between 12 June and 16 November; 54 were sampled in 2008 between 3 June and 14 November; and 65 were sampled in 2009 between 1 June and 20 October. Visits were performed during summer and early fall to exploit the predicted bovine peak in E. coli O157 prevalence and the period when starlings start congregating in large flocks and visiting farms. Upon arrival at the farm (time range: 8:30-16:40 h, the peak daily activity period of starlings), one to three observers recorded the number of starlings in barns, feed storage and manure storage areas during four 5-min periods spaced evenly over a 1-h observation period, following a standard protocol recommended by research partners from the USDA National Wildlife Research Center (Great Plains Field Station, Bismark, ND, USA). The final count recorded for each farm was based on the highest number of birds recorded among these recording periods. Training of personnel used for bird counts was done beforehand and consisted of instructions on recognizing starlings and differentiating them from other avian species.

\section{Sampling}

Fresh faecal pats samples of approximately $25 \mathrm{~g}$ were collected from the first 30 milking cows that were observed defecating at the time of each visit. Each faecal pat was stirred, collected and stored in WhirlPak bags using sterile tongue depressors. Samples were stored on ice during transportation to the laboratory.

\section{Faecal sample processing}

Buffered peptone water at a ratio of $1: 10$ was added to ten grams of bovine faecal samples and homogenized in a laboratory stomacher for $30 \mathrm{~s}$ at five strokes per second 
and incubated at $37^{\circ} \mathrm{C}$ for $18-24 \mathrm{~h}$ for enrichment. Escherichia coli O157:H7 present in any 1-ml aliquot of the overnight culture, along with a positive control, was concentrated with anti-O157 immunomagnetic beads (Dynal, Oslo, Norway). Seventy-five microlitre of bead mixture was plated onto sorbitol-MacConkey agar plates containing cefixime $(50 \mathrm{ng} / \mathrm{ml}$; Sigma Chemical Co., St. Louis, MO, USA) and potassium tellurite $(2.5 \mathrm{mg} / \mathrm{ml}$; Sigma Chemical Co.) (CT-SMAC) and incubated for $18 \mathrm{~h}$ at $37^{\circ} \mathrm{C}$. Up to five suspected colonies (white colonies) per sample were transferred from CT-SMAC to E. coli 4 -methylumbelliferyl- $\beta$-D-glucuronide agar (EC Mug; EC media: Neogen-Acumedia Manufacturers Inc., Lansing, MI, USA; MUG: Biosynth AG, Staad, Switzerland) plates and then incubated for $24 \mathrm{~h}$ at $37^{\circ} \mathrm{C}$. MUG negative (not glowing colonies) isolates were transferred to MAC plates and incubated for $24 \mathrm{~h}$ at $37^{\circ} \mathrm{C}$. A latex agglutination assay (Oxoid Ltd., Nepean, ON, Canada), for the detection of the O157 antigen, was used to confirm lactose positive isolates (purple colonies). Up to two isolates from each positive sample were then stored at $-70^{\circ} \mathrm{C}$ in a solution with 30\% buffered glycerol. Cultures of stored samples were recovered on CT-SMAC plates, incubated at $37^{\circ} \mathrm{C}$ for $18-24 \mathrm{~h}$ and then stored at $4^{\circ} \mathrm{C}$ for molecular analysis. Escherichia coli O157:H7 suspect colonies were tested by PCR for the presence of $r f b \mathrm{E}$. Isolates confirmed as E. coli $\mathrm{O} 157$ by the presence of the $r f b \mathrm{E}$ gene were subsequently subtyped by multiple-locus variable-number tandem repeat analysis (MLVA) (Williams et al., 2011).

\section{Questionnaire}

A questionnaire was developed and administered to the farm owner or manager during a face-to-face interview at the time of the first visit. The questionnaire, pre-tested during the early stages of the study while gathering information on farms included in the study, was written in English, and consisted of closed and open-ended questions. Closed questions (e.g. checklist) were asked to gather information pertaining to areas where birds concentrate, and about management and infrastructure of the farm. Open-ended questions (e.g. fill in the blank) were used to capture numerical data on a continuous scale on demographic characteristics and on the number of birds observed on farms. Numerical data were exported and treated as continuous variables in the dataset. When ranges were provided instead of single values, the midpoint of the range was used.

Validation of the questionnaire was performed for questions pertaining to time-invariant characteristics (e.g. type of barns, type of ventilation systems), by assessing the repeatability of the questionnaires that were administered twice. However, for time-variant predictors, such as the concentration of birds observed on different areas or the number of animals on site, responses could not be compared between visits, but they were collected by the researcher and not dependent on farmer's responses.

Information was collected on the following general areas: farm management practices, bird infestation and environmental characteristics of the farm (available upon request to the corresponding author). The questionnaire was broken into seven sections and gathered the following information:

1 Demographic data: herd size, number of calves, heifers and milking cows, and the presence and the number of other domestic and wild animals.

2 Bird data: most common species of birds seen, number of starlings in barns, on farms and on fields, and distance from closest known night roost site.

3 Perception of bird activity: if starlings were considered a problem on the farm, in which season they were present, peak activity period, preferred location for starlings, and the presence of starling nesting sites.

4 Farm management/facilities: number of barns, type of calf housing, roof structure, ventilation system, type of stall bedding, cattle additions, contact between adult and young animals.

5 Feeding practices: type of feed and feed storage.

6 Manure management: type of storage and frequency of removal.

7 Environmental variables: water sources on farm and temperature and precipitation on the day the questionnaire was given.

\section{Data management: exclusions}

Of the total 9030 individual observations included originally in the dataset, 90 observations corresponding to faecal pat samples collected from heifers were collected unintentionally. These samples corresponded to both visits from one farm and to the first visit of the farm that was sampled three times. Only samples from milking cows were collected and analysed (with the exception of the 90 samples mentioned above), given the majority of the study farms raise their calves off-site. Thus, a total of 8940 observations from 149 farms were utilized in the risk factors analyses.

\section{Statistical analyses}

Associations between bird infestation, environmental, housing and management variables identified in the farm survey, and the proportion of E. coli O157-contaminated faecal samples from cattle were modelled using a multilevel logistic regression model with random effects to control for clustering of cattle nested within visits within 
farms. Mixed-effects models were fitted using adaptive quadrature with the 'xtmelogit' command (Rabe-Hesketh et al., 2002) in Stata 11 (StataCorp LP, College Station, TX, USA).

We examined all the variables in a univariable screen of fixed effects using logistic regression models with random intercepts for county, farm and visit. Owing to the very small variance component found for county (variance range: $1.0 \mathrm{e}^{-18}-1.0 \mathrm{e}^{-21}$ ), this random effect was removed from the model; thus, the univariable analysis used mixed-level logistic regression models with random intercepts only for farm and visit. The linearity assumption between the $\log$ odds of the outcome and continuous predictors was assessed using graphical methods (i.e. lowess smoothing of the logit of the outcome on the continuous predictor). If the assumption was not met, depending on the shape of these relationships, the predictor variable was categorized unless it was more appropriately transformed (e.g. natural logarithm) or modelled with the addition of a quadratic term (Dohoo et al., 2009). Furthermore, a pair-wise correlation analysis was performed among all the variables significantly associated with the outcome at the $40 \%$ level in the univariable analysis. We used the Spearman's rank correlation statistic to identify possible collinearity between variables. If the value of the correlation statistic between two presumably independent variables was $|0.8|$ or greater (Mason and Perreault, 1991), only one of the variables was selected for inclusion in the multivariable model based on its biological plausibility or completeness and quality of collected data (Dohoo et al., 2009).

During model building, an initial main effects model was built that included all predictors in the univariable analysis significantly associated with the outcome at the $40 \%$ level $(P \leq 0.40)$. A manual backward elimination procedure was then conducted until only statistically significant $(P \leq 0.05$ based on the Wald chi-square test) main effects and confounding variables remained. On the basis of our causal diagram (Fig. 1), bird infestation, represented by variables like number of birds and number of starlings per milking cow (estimated as the number of starlings counted during the farm's visit divided by the total number of milking cows) could be considered either primary predictor variables or intervening variables if they could intervene in the causal pathway between farm management or environmental variables and the predicted outcome. In the latter case, these bird-related variables should not be included with other management and environmental variables in the multivariable model because the true causal effects of the variables earlier in the causal pathway would not be estimated correctly (Dohoo et al., 2009). Consequently, we explored multivariable models that both included and excluded bird-related variables. During the removal of statistically non-significant variables from the initial main effects model, we evaluated the potential confounding effect of these variables. A confounding variable was defined as any non-intervening variable that resulted in a $\geq 20 \%$ change in the coefficient of a statistically significant variable after removal (Dohoo et al., 2009). Additionally, we considered the following variables, based on a priori consideration of our causal model (Fig. 1), as potential confounders and interaction terms for all models: season (summer and fall), total number of milking cows and region (North-west, Northcentre and North-east). Type of feed storage (e.g. silos, bagged, bunkers), type of feed (e.g. TMR, silage, grazing), location of feeding (e.g. inside or outside the barn or

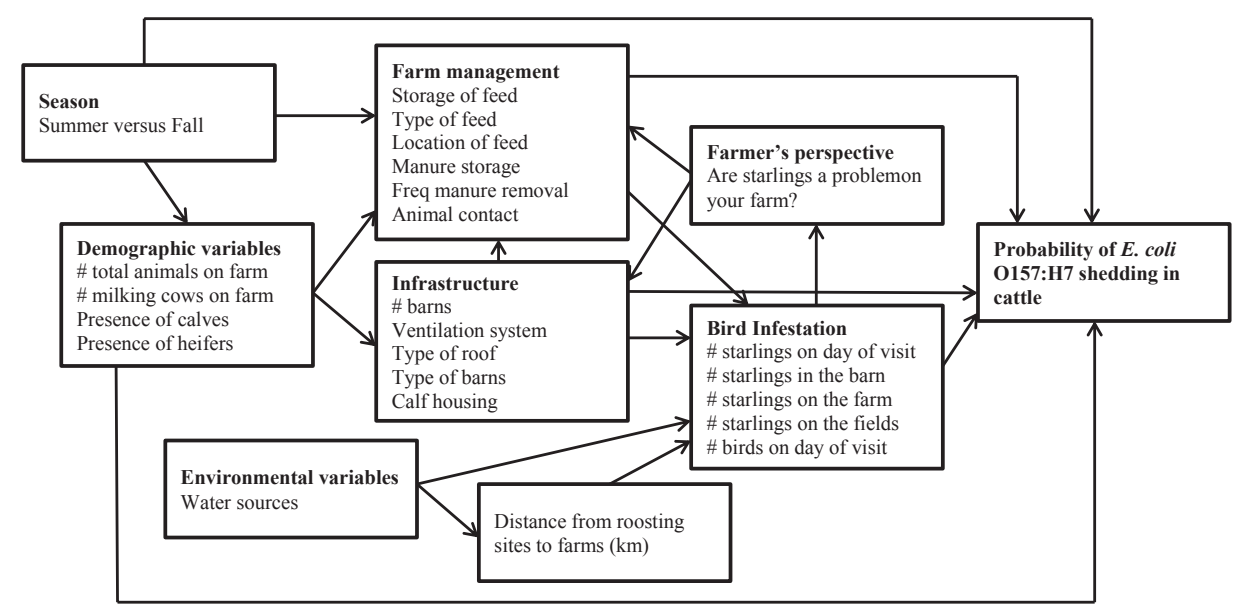

Fig. 1. Causal diagram of the association between farm management, demographic, infrastructural, environmental and bird infestation variables with the presence of Escherichia coli 0157 in faecal pat samples from dairy cattle. 
both), type of manure storage (e.g. lagoon, pile or their combination), frequency of manure removal (e.g. every milking, daily, other) and water sources (e.g. lagoon, pond, river, stream, other) were considered a priori confounders of the models that included bird-related variables. All possible two-way interaction terms between all predictors significantly associated $(P \leq 0.05)$ with the outcome in our main effects model (and between these predictors and confounders established a priori) were added individually to the main effects model and tested for statistical significance at the $5 \%$ level. Main effects that were part of significant interaction terms $(P \leq 0.05)$ would have been retained in the model regardless of their individual levels of statistical significance.

Diagnostics of residuals from the final multivariable model included the estimation and analysis of predicted values of the random effects (i.e. farm- and visit-level residuals) in the model (known as best linear unbiased predictors or BLUPs), and Pearson and Deviance residuals for observations at the lowest level (i.e. bovine samples). Normal quantile plots of BLUPs and residual plots were visually examined to assess general model fit and to identify potential outliers and influential observations (Robinson, 1991). Extreme observations were first evaluated for recording error and were then assessed for changes in the interpretation of our models if removed. Finally, odds ratios (OR) and their respective 95\% confidence intervals were estimated for predictors included in the final multivariable model. Additionally, we estimated the per cent of variation in the outcome explained at the visit and farm levels for the final models using a latent variable technique (Dohoo et al., 2009).

\section{Results}

\section{Characteristics of cattle and bird populations on study farms}

The median herd size of our study farms was 175 animals $(\mathrm{IQR}=100-315)$, while the median number of milking cows present was $70(\mathrm{IQR}=32-154)$.

A total of 86 of 8940 (1\%) bovine faecal samples tested positive for E. coli O157. By season, 70 of the $86(81 \%)$ positive samples were collected in summer (June-September) and $19 \%(16 / 86)$ were collected during fall months (October-November). At the farm level, 35 of the 149 (24\%) dairy farms had at least one cow testing positive for $E$. coli O157.

Twenty-nine and 23 of the 35 E. coli O157-infected farms had a visible number of birds and starlings at the time of the visit (at least one bird counted at the time of the visit), respectively. The median number of birds counted on E. coli O157 positive farms was 20 $(\mathrm{IQR}=10-100$, range $=0-4000)$, whereas the median number of starlings was $8(\mathrm{IQR}=0-50$, range $=0-3000)$ (Table 1). In contrast, the number of non-positive farms $(n=114)$ that had 0 starlings and birds counted was 31 and 10, respectively. The median number of starlings counted on non-positive farms was 10 (IQR $=0-50$, range $=0-3000)$, whereas the median number of birds was $50 \quad(\mathrm{IQR}=10-125$, range $=0-4000)$. Ninety-four dairy producers $(63 \%)$ stated that the presence of starlings was a problem. We found at least one starling on $114(76 \%)$ farms at the time of any of the visits, and 74 (65\%) of these owners stated that starlings were a problem. Further, farmers in 17 of the $35(49 \%)$ E. coli O157 positive sites and in 72 of the $114(63 \%)$ negative farms considered starlings a problem.

Table 1. Descriptive statistics of variables pertaining to farm demography and bird infestation from our study of the on-farm prevalence of Escherichia coli 0157 in dairy herds in Ohio (2007-2009)

\begin{tabular}{|c|c|c|c|c|c|c|c|c|}
\hline \multirow[b]{2}{*}{ Variable } & \multicolumn{4}{|c|}{ Infected farms $(n=36)$} & \multicolumn{4}{|c|}{ Non-infected farms $(n=114)$} \\
\hline & Mean & Median & IQR & Range & Mean & Median & IQR & Range \\
\hline Total number of cattle & 321 & 400 & $125-425$ & $30-750$ & 333 & 175 & $100-300$ & $26-5000$ \\
\hline Number of milking cows & 156 & 60 & $30-300$ & $30-950$ & 183 & 90 & $55-210$ & $24-2600$ \\
\hline Number of birds seen per visit & 225 & 20 & $0-100$ & $0-4000$ & 123 & 50 & $10-125$ & $0-4000$ \\
\hline Number of birds seen per visit per milking cow & 2 & 1 & $0-1$ & $0-14$ & 1 & 0.4 & $0-1$ & $0-14$ \\
\hline Number of starlings seen per visit & 157 & 8 & $0-50$ & $0-3000$ & 71 & 10 & $0-50$ & $0-3000$ \\
\hline Number of starlings seen per visit per milking cow & 1 & 0.05 & $0-1$ & $0-11$ & 0.5 & 0.05 & $0-0.3$ & $0-11$ \\
\hline \multicolumn{9}{|l|}{ Distance from roosting sites to study farms $(\mathrm{km})$} \\
\hline Closest roost site & 41.9 & 31.5 & $18.1-58.6$ & $1.9-230$ & 57.9 & 32.5 & $12.8-67.1$ & $1.9-511.8$ \\
\hline Lime lakes & 60.6 & 53.9 & $50.9-74.3$ & $9.8-250.2$ & 74.6 & 53.6 & $30.3-80.4$ & $9.8-532.1$ \\
\hline Morton & 51.3 & 42.2 & $37.2-59.9$ & $2.4-235.7$ & 68.5 & 49.3 & $26.8-80.9$ & $2.4-517.7$ \\
\hline Apple creek & 47.6 & 31.5 & $19.3-60.3$ & $9.2-230$ & 65.2 & 37.7 & $21.1-76.3$ & $3.2-511.8$ \\
\hline South Rittman & 50.5 & 41.1 & $35.8-58.6$ & $1.9-234.2$ & 67.9 & 48.7 & $26.5-79.5$ & $1.9-516.4$ \\
\hline
\end{tabular}


Based on the occurrence percentage at our study sites, the following bird species were predominant: starlings, house sparrows (Passer domesticus) and barn swallows (Hirundo rustica), followed by cowbirds (Molothrus ater), pigeons (Columba livia), doves (Zenaida macroura), gulls (Laridae) and killdeer (Charadrius vociferus) (Table 1).

Four night roosting sites were identified in the study catchment area and were used by starlings, as well as by other bird species. The median distances between our study farms and any of these night roosts were $\leq 58 \mathrm{~km}$ (Table 1).

\section{Risk factor analysis}

Variables significantly associated with the probability of a sample testing positive for E. coli $\mathrm{O} 157$ in the univariable analysis $(P \leq 0.40)$ included the following: number of birds per milking cow, number of starlings per milking cow, contact between adult cattle and calves, the presence of calves on farm, number of ventilation systems used on the farm, type of manure storage, frequency of manure removal and distance from the closest roost site to the farm (Table 2). The number of birds per milking cow and number of starlings seen in fields, on farm and in barns were all highly correlated (Pearson's rho $r \geq 80 \%$ ) with the number of starlings per milking cow, so only this latter variable was used in our multivariable models.

The final multivariable mixed-effects model that excluded bird-related variables included the following variables: contact between adults and calves, type of manure storage and number of ventilation systems (Model 1; Table 3). The odds of having an E. coli O157 positive sample were significantly greater on farms where there was contact between adults and calves (Table 3). Furthermore, the prevalence of E. coli O157 in bovine faecal samples was significantly greater on farms that used either manure piles or lagoons compared with farms that used a combination of manure storage systems (Table 3). The question included in the questionnaire pertaining to ventilation systems consisted of a closed, checklist-type of

Table 2. Univariable mixed-effects ${ }^{\mathrm{a}}$ logistic regression analysis for the association between the presence of Escherichia coli 0157 in bovine faecal pat samples and farm management, environmental and bird-related variables from our study of dairy herds in Ohio (2007-2009)

\begin{tabular}{|c|c|c|c|c|}
\hline Variable $^{\mathrm{b}}$ & $\%$ of study farms (proportion) ${ }^{c}$ & OR & OR $95 \% \mathrm{Cl}$ & $P$-value \\
\hline Number of birds per milking cow & $93(139 / 149)$ & 1.3 & $1.1-1.5$ & 0.004 \\
\hline Number of starlings per milking cow & $68(102 / 149)$ & 1.4 & $1.1-1.7$ & 0.002 \\
\hline Number of starlings in barns & $46(69 / 149)$ & 1.01 & $1.00-1.01$ & 0.011 \\
\hline \multicolumn{5}{|l|}{ Manure storage } \\
\hline Lagoon & $55(71 / 130)$ & Ref & Ref & Ref \\
\hline Pile & $22(28 / 130)$ & 0.9 & $0.3-2.7$ & 0.922 \\
\hline Combinations & $24(31 / 130)$ & 0.1 & $0.02-0.8$ & 0.026 \\
\hline \multicolumn{5}{|l|}{ Contact between adults and calves } \\
\hline No & $85(127 / 149)$ & Ref & Ref & Ref \\
\hline Yes & $15(22 / 149)$ & 2.1 & $0.6-7.4$ & 0.237 \\
\hline \multicolumn{5}{|l|}{ Presence of calves } \\
\hline No & $43(64 / 149)$ & Ref & Ref & Ref \\
\hline$Y_{e s}^{d}$ & $57(85 / 149)$ & 0.6 & $0.2-1.5$ & 0.254 \\
\hline \multicolumn{5}{|l|}{ Distance from farm to closest roost site } \\
\hline$<32.52 \mathrm{~km}$ (median) & $50(74 / 149)$ & Ref & Ref & Ref \\
\hline$>32.52 \mathrm{~km}$ & $50(75 / 149)$ & 0.7 & $0.2-1.8$ & 0.412 \\
\hline \multicolumn{5}{|l|}{ Ventilation system } \\
\hline One system & $49(70 / 142)$ & Ref & Ref & Ref \\
\hline Two systems & $18(26 / 142)$ & 0.1 & $0.1-1.4$ & 0.082 \\
\hline Three systems & $13(18 / 142)$ & 1.4 & $0.4-4.7$ & 0.628 \\
\hline Four or more systems & $20(28 / 142)$ & 0.9 & $0.3-3.0$ & 0.883 \\
\hline \multicolumn{5}{|l|}{ Manure removal } \\
\hline Daily & $47(59 / 126)$ & Ref & Ref & Ref \\
\hline Every milking & $39(49 / 126)$ & 2.7 & $0.8-8.9$ & 0.110 \\
\hline Other (weekly, etc.) & $14(18 / 126)$ & 1.2 & $0.2-7.4$ & 0.837 \\
\hline
\end{tabular}

${ }^{\mathrm{a}}$ Random intercepts for farm and visit.

${ }^{\mathrm{b}}$ Contrasts were constructed between categories within categorical variables.

${ }^{\mathrm{C}}$ Estimated as the number of farms where the characteristic of interest is present divided by the total number of study farms (in the case of numbers it refers to at least 1 unit being present).

${ }^{\mathrm{d}}$ The presence of calves on at least one visit. 
Table 3. Multivariable mixed-effects ${ }^{\mathrm{a}}$ logistic regression models for the association between farm management and environmental variables and the presence of Escherichia coli 0157 in faecal pats from dairy cattle without (Model 1) and with (Model 2) the inclusion of bird infestation variables from our study of dairy herds in Ohio (2007-2009)

\begin{tabular}{|c|c|c|c|c|c|c|}
\hline \multirow[b]{2}{*}{ Variable } & \multicolumn{3}{|l|}{ Model 1} & \multicolumn{3}{|l|}{ Model 2} \\
\hline & OR & OR $95 \% \mathrm{Cl}$ & $P$-value & OR & OR $95 \% \mathrm{Cl}$ & $P$-value \\
\hline Contact between adult cattle and calves & 4.5 & $1.2-17.3$ & 0.029 & 4.2 & $1.1-15.6$ & 0.034 \\
\hline \multicolumn{7}{|l|}{ Type of manure storage } \\
\hline Pile versus Lagoon & 1.2 & $0.4-4.0$ & 0.715 & 1.4 & $0.4-4.4$ & 0.599 \\
\hline Lagoon versus combinations & 8.03 & $1.3-50.0$ & 0.025 & 7.9 & $1.3-50.0$ & 0.027 \\
\hline Pile versus combination & 10.2 & $1.3-79.8$ & 0.027 & 10.9 & $1.4-82.9$ & 0.021 \\
\hline \multicolumn{7}{|l|}{ Ventilation system $^{\text {b }}$} \\
\hline 2 systems versus 1 system & 0.1 & $0.01-1.3$ & 0.085 & 0.1 & $0.01-1.5$ & 0.104 \\
\hline 3 systems versus 1 system & 3.6 & $0.9-14.6$ & 0.078 & 2.3 & $0.5-10.4$ & 0.261 \\
\hline$>4$ systems versus 1 system & 1.7 & $0.5-6.65$ & 0.413 & 1.7 & $0.4-6.8$ & 0.472 \\
\hline 2 systems versus 3 systems & 0.03 & $0.002-0.5$ & 0.014 & 0.1 & $0.004-0.9$ & 0.040 \\
\hline 2 systems versus $>4$ systems & 0.1 & $0.004-1.0$ & 0.047 & 0.1 & $0.006-1.2$ & 0.065 \\
\hline 3 systems versus $>4$ systems & 2.1 & $0.4-9.7$ & 0.364 & 1.4 & $0.3-7.6$ & 0.694 \\
\hline Number of starlings per milking cow & - & - & - & 1.3 & $1.0-1.7$ & 0.026 \\
\hline Variance components $^{c}$ & $\operatorname{Var}(\mathrm{SE})$ & \multicolumn{5}{|c|}{$\operatorname{Var}(\mathrm{SE})$} \\
\hline Farm & $0.1(1.3)$ & \multicolumn{5}{|c|}{$0.8(1.1)$} \\
\hline Visit & $2.9(2.1)$ & \multicolumn{5}{|c|}{$1.8(1.3)$} \\
\hline
\end{tabular}

${ }^{a}$ Multivariable mixed-effect logistic regression model with random intercepts for farm and visit.

bald test for global variable $\chi^{2}=5.04, P$-value $=0.17$.

'Variance components (and SE) for intercept-only model: Farm $=1.2(1.5)$, Visit $=3.6(2.0)$.

question, which aimed to specify all types of ventilation systems present on the milking barn(s). Associations between the most common types of ventilation systems and the probability of a faecal sample to be positive to $E$. coli O157:H7 were assessed. Doors and open-sided barns, which were reported most frequently, individually and in combination with other systems (for instance, 'doors' was included in 14 of the 18 combinations of ventilation systems provided in the farmers' responses), were tested (as dichotomous variables) as separate covariates. These variables were characterized by the presence-absence on the farm and were modelled both singly and in conjunction with other ventilation systems, if present. However, they were not significantly $(P<0.05)$ associated with the outcome in the bivariable and multivariable analyses. Given that in the majority of cases, more than one ventilation systems was employed, the number rather than type of system was categorized and modelled as a polychotomous variable. The variable pertaining to the number of ventilation systems was not statistically significant $(P<0.05)$ but acted as a confounding variable, and hence, it was included in the final multivariable model. However, based on contrasts, the odds of a bovine faecal pat sample testing positive for E. coli $\mathrm{O} 157$ were significantly reduced on farms that used two types of ventilation systems compared with farms that used three or more types of ventilation systems (Table 3 ).
In the second multivariable model, which included bird-related variables, we found that for each unit increase in the number of starlings per milking cow, the odds of a faecal pat testing positive for E. coli O157 increased almost 1.3 times (Model 2; Table 3). The other management and environmental variables had similar measures of association in this model compared with the model that excluded bird-related variables (Model 1 versus Model 2; Table 3).

For the model without the inclusion of the bird infestation variable, the proportion of variation in the outcome explained at the visit and farm levels was $46 \%$ and $2 \%$, respectively. When the number of starlings seen on farm per capita (i.e. per milking cow) was included in the model, the proportion of variation explained at the visit and farm levels was $31 \%$ and $14 \%$, respectively (Table 3 ). Visual assessment of residuals did not identify any potential outliers or highly influential observations on our final multivariable models.

\section{Discussion}

This is one of the first prospective studies to study the potential role that wild birds (and in particular, starlings) play in the epidemiology of E. coli O157 in dairy cattle. The number of starlings per milking cow, among other farm management factors, was significantly associated 
with the presence of E. coli O157:H7 in bovine faeces. Bird infestation was considered a problem by $76 \%$ of farmers and the number of starlings per milking cow showed a strong association with the presence of E. coli O157 in bovine faecal samples in univariable and multivariable analyses. Starlings and other peri-domestic species of wild birds, such as house sparrows (Passer domesticus) and rock pigeons (Columba livia), are attracted to livestock facilities. Therefore, the congregation of large numbers of birds around these facilities appears to pose a risk for the spread of pathogens to livestock (Linz et al., 2007; LeJeune et al., 2008). Our causal diagram predicted that the number of starlings per milking cow might act as an intervening variable in our models. Many farm management variables, including feed, feed storage, manure storage, frequency of manure removal, on-farm water sources and distance to closest roost site, might influence both the presence and the quantity of birds. However, inclusion of the variable pertaining to the number of starlings per milking cow did not have a great effect on the measures of association of farm management and environmental variables in our multivariable models. Our results are supported by the findings of Williams et al. (2011), who used MLVA to examine the relationships among E. coli O157:H7 isolates obtained from the gastrointestinal tracts of starlings and the faecal pats of dairy cattle sampled from our study farms. Although they were only able to capture starlings from 26 farms, they did identify three indistinguishable allelic groups that contained isolates from more than one farm, and two of these groups included isolates obtained from starlings and cattle isolates (Williams et al., 2011). The distances among farms sharing a common allelic group were generally consistent with the distances travelled by starlings during this time of year based on a radio-tracking study of these birds from a subset of our study farms (LeJeune et al., 2008; Homan, 2011). Radio-tracked birds in this study often travelled moderate distances $(\sim 20 \mathrm{~km})$ between their night roosts and their preferred daytime feeding location/dairy farm where most of their daily activities were confined to a radius of $<2 \mathrm{~km}$. The flights of starlings to dairy farms in this area were fairly direct, but returning flights to night roosts in the late afternoon and early evening were less direct and involved stopping at several dairy farms (LeJeune et al., 2008; Homan, 2011). Although we found no relationship between the prevalence of E. coli O157:H7 in cow faecal pats and the distance to the nearest night roost identified in our study area, more complex spatial analyses concerning the clustering of $E$. coli O157:H7 positive cow pats around night roosts and other focal points of bird activity may be warranted.

We found that $24 \%$ of dairy farms and approximately $1 \%$ of cow pats tested positive to E. coli O157 in our study area. These results are in accordance with previous studies performed in dairy cattle, where the estimates of herd prevalence ranged from $0.2 \%$ to $49 \%$ (Dunn et al., 2004; Hussein and Sakuma, 2005) and animal-level prevalence from $2.3 \%$ to $8 \%$ in adult cattle (Hancock et al., 1998; Cobbold et al., 2004; Kuhnert et al., 2005). In addition to bird-related variables, the prevalence of E. coli O157 based on our models appears to be associated with the following farm management variables: contact between adults and calves, use of manure piles and the presence of $\geq 3$ ventilation systems. In terms of the per cent variation explained at the farm and visit levels, most of the variation in the outcome was explained at the visit rather than farm level. This seems consistent with the intermittent nature in which E. coli $\mathrm{O} 157$ is detected on farms.

The relationship between the prevalence of E. coli $\mathrm{O} 157$ in milking cattle and contact with younger animals is consistent with the previous epidemiological studies in cattle. In younger cattle, the shedding of E. coli O157 tends to be more frequent, occurs for longer periods of time and at higher concentrations compared with mature animals (Paiba et al., 2003; Synge et al., 2003; Gunn et al., 2007). Consequently, the presence of younger animals on the farm may act as a reservoir for re-infection of milking animals. Thus, off-site rearing of calves and heifers intended to control production-limiting diseases, such as Johne's disease, may likewise be advantageous for controlling E. coli $\mathrm{O} 157$ in milking animals (Hanson, 2005).

Manure storage areas provide additional foraging opportunities for birds and other wildlife because manure usually contains grains or other foods that were dropped during feeding or were defecated by cattle. Piles could be considered a high-risk method of storing manure compared with lagoons because piles are less confined (i.e. piles can be located in farm yards or fields), may attract wildlife and have no anaerobic decomposition, a process that may reduce E. coli O157 viability. Interestingly, in our multivariable models, there was no significant difference in the prevalence of E. coli O157 among farms with lagoons or piles, but there was an increased risk associated with the use of only one of these approaches compared with the use of multiple management practices. The use of multiple systems for manure management may be a proxy for other factors influencing reduction in E. coli $\mathrm{O} 157$ prevalence; for example, it may reflect an increased awareness of biosecurity.

Five types of ventilation systems were used on the study farms including doors, fans, curtains, ridge-vent and open-sided ventilation, with the first three types being in order of most frequently used. Most farms used combinations of two or more of the ventilation systems. 
Non-mechanical ventilation systems probably provide easier access for birds to enter and thus should show increased odds for E. coli $\mathrm{O} 157$ prevalence. However, in our study, we found that the number of ventilation systems, rather than the type of system, was associated with the prevalence of E. coli O157. Although in our global test the number of ventilation systems was not statistically significant, this variable was a confounder in our multivariable model. Multiple ventilation systems may be related to recent construction or herd expansion with potential negative consequences to biosecurity. Berends et al. (2008) found that the use of mechanical ventilation contributed to an environment that reduced the survival of $E$. coli O157 (Paiba et al., 2003). Our models did not support the research of Berends et al., (2008), showing a farm-site environment less conducive to E. coli O157.

It is important to recognize the limitations of a crosssectional study design when interpreting the results of this study (Dohoo et al., 2009). The prevalence of E. coli O157 carriage, and not incidence, was measured; thus, it is difficult to disentangle factors associated with cattle shedding E. coli O157:H7 and factors associated with the duration of E. coli O157 shedding. However, controlling the prevalence would still have an impact on public health.

Our finding that the number of starlings per milking cow was significantly associated with the prevalence of $E$. coli $\mathrm{O} 157: \mathrm{H} 7$ in dairy cattle, coupled with the isolation of indistinguishable E. coli O157:H7 MLVA subtypes from starlings and cattle on several farms (Williams et al., 2011) and the nature of starling movements among these farms (LeJeune et al., 2008; Homan, 2011), reinforces our hypothesis that starlings have a role in increasing the prevalence of E. coli O157:H7 among milking cattle and in the transmission of this bacterium among dairy farms. There are still knowledge gaps in terms of the specific role starlings have as vectors of transmission of E. coli O157:H7. Nevertheless, understanding the effect of farm management practices on bird populations may provide more non-lethal tools to manage starling numbers on farms, thus reducing environmental contamination and transmission of E. coli O157:H7 to cattle.

\section{Acknowledgements}

The original study was funded by the United States Department of Agriculture through their National Research Initiative (USDA-NRI), Epidemiological Approaches to Food Safety Grant \# 2006-01227. The computational infrastructure for this research was obtained with the support of the Canada Foundation for Innovation and the Ontario Ministry of Research and Innovation through a grant to D.L. Pearl.

\section{References}

Berends, I. M., E. A. Graat, W. A. Swart, M. F. Weber, A. W. van de Giessen, T. J. Lam, A. E. Heuvelink, and H. J. van Weering, 2008: Prevalence of VTEC O157 in dairy and veal herds and risk factors for veal herds. Prev. Vet. Med. 87, 301-310.

Cobbold, R. N., D. H. Rice, M. Szymanski, D. R. Call, and D. D. Hancock, 2004: Comparison of Shiga-toxigenic Escherichia coli prevalences among dairy, feedlot, and cow-calf herds in Washington State. Appl. Environ. Microbiol. 70, 4375-4378.

Daniels, M. J., M. R. Hutchings, and A. Greig, 2003: The risk of disease transmission to livestock posed by contamination of farm stored feed by wildlife excreta. Epidemiol. Infect. 130, 561-568.

Dohoo, I., W. Martin, and H. Stryhn, 2009: Veterinary Epidemiologic Research, 2nd edn. AVC Inc., Charlottetown, Prince Edward Island.

Dunn, J. R., J. E. Keen, and R. A. Thompson, 2004: Prevalence of Shiga-toxigenic Escherichia coli O157:H7 in adult dairy cattle. JAVMA 224, 1151-1158.

Fenlon, D. R., 1985: Wild birds and silage as reservoirs of Listeria in the agricultural environment. J. Appl. Bacteriol. 59, 537-544.

Gunn, G. J., I. J. McKendrick, H. E. Ternent, F. Thomson-Carter, G. Foster, and B. A. Synge, 2007: An investigation of factors associated with the prevalence of verocytotoxin producing Escherichia coli $\mathrm{O} 157$ shedding in Scottish beef cattle. Vet. J. 174, 554-564.

Hancock, D. D., T. E. Besser, D. H. Rice, E. D. Ebel, D. E. Herriot, and L. V. Carpenter, 1998: Multiple sources of Escherichia coli $\mathrm{O} 157$ in feedlots and dairy farms in the Northwestern USA. Prev. Vet. Med. 35, 11-19.

Hanson, M., 2005: Completely calves. Bovine Practitioner September, $50-58$.

Homan, H. J., 2011: Site use of European starlings captured and radio tagged at Texas feedlots during winter. In: Proceedings 24th Vertebrate Pest Conference, University of California, Davis, pp. in press.

Hussein, H. S., and T. Sakuma, 2005: Prevalence of shiga toxin-producing Escherichia coli in dairy cattle and their products. J. Dairy Sci. 88, 450-465.

Kuhnert, P., C. R. Dubosson, M. Roesch, E. Homfeld, M. G. Doherr, and J. W. Blum, 2005: Prevalence and risk-factor analysis of Shiga toxigenic Escherichia coli in faecal samples of organically and conventionally farmed dairy cattle. Vet. Microbiol. 109, 37-45.

LeJeune, J. T., J. Homan, G. Linz, and D. L. Pearl 2008: Role of the European starling in the transmission of E. coli O157 on dairy farms. In: Proceedings 23rd Vertebrate Pest Conference, University of California, Davis, pp. 31-34.

Linz, G. M., H. J. Homan, S. M. Gaulker, L. B. Penry, and W. J. Bleier 2007: European starlings: a review of an invasive species with far-reaching impacts. In: Witmer, G. W., W. C. Pitt, and K. A. Fagerstone (eds), Managing Invasive Verte- 
brate Species: Proceedings of an International Symposium, pp. 378-386. USDA/APHIS/National Wildlife Research Center, Fort Collins, CO, USA.

Luechtefeld, N. A., M. J. Blaser, L. B. Reller, and W. L. Wang, 1980: Isolation of Campylobacter fetus subsp. jejuni from migratory wild fowl. J. Clin. Microbiol. 12, 406-408.

Mason, C. H., and W. D. Perreault, 1991: Collinearity, power and interpretation of multiple regression analysis. J. Mark. Res. 28, 268-280.

Paiba, G. A., J. W. Wilesmith, S. J. Evans, S. J. Pascoe, R. P. Smith, S. A. Kidd, J. B. Ryan, I. M. Mclaren, S. A. Chappell, G. A. Willshaw, T. Cheasty, N. P. French, T. W. Jones, H. F. Buchanan, D. J. Challoner, A. D. Colloff, M. P. Cranwell, R. G. Daniel, I. H. Davies, J. P. Duff, R. A. Hogg, F. D. Kirby, M. F. Millar, R. J. Monies, M. J. Nicholls, and J. H. Payne, 2003: The prevalence of faecal excretion of verocytotoxigenic Escherichia coli (VTEC O157) in cattle in England and Wales. Vet. Rec. 153, 347-353.

Pimentel, D., L. Lach, R. Zuniga, and D. Morrison 1999: Environmental and Economic Costs Associated with Non-Indigenous Species in the United States. Cornell University, Ithaca, NY. http://www.news.cornell.edu/releases/Jan99/species_costs.html (accessed on 4 April 2011).

Pimentel, D., R. Zuniga, and D. Morrison, 2005: Update on the environmental and economic costs associated with alieninvasive species in the United States. Ecol. Econ. 52, 273288.
Quessy, S., and S. Messier, 1992: Campylobacter spp. and Listeria spp. in ring-billed gulls (Larus delwarensis). J. Wildl. Dis. 28, 526-531.

Rabe-Hesketh, S., A. Skrondal, and A. Pickles, 2002: Reliable estimation of generalized linear mixed models using adaptive quadrature. SJ. 2, 1-21.

Robinson, G. K., 1991: That BLUP is a good thing: the estimation of random effects. Statist. Sci. 6, 15-32.

Synge, B. A., M. E. Chase-Topping, G. F. Hopkins, I. J. McKendrick, F. Thomson-Carter, D. Gray, S. M. Rusbridge, F. I. Munro, G. Foster, and G. J. Gunn, 2003: Factors influencing the shedding of verocytotoxin-producing Escherichia coli O157 by beef suckler cows. Epidemiol. Infect. 130, 301-312.

Van Donkersgoed, J., J. Berg, A. Potter, D. Hancock, T. Besser, D. Rice, J. LeJeune, and S. Klashinsky, 2001: Environmental sources and transmission of Escherichia coli O157 in feedlot cattle. Can. Vet. J. 42, 714-720.

Wetzel, A. N., and J. T. LeJeune, 2006: Clonal dissemination of Escherichia coli O157:H7 subtypes among dairy farms in Northeast Ohio. Appl. Environ. Microbiol. 72, 2621-2626.

Williams, M. L., D. L. Pearl, and J. T. LeJeune 2011: Multiplelocus variable-nucleotide tandem repeat subtype analysis implicates European starlings as biological vectors of Escherichia coli O157:H7 in Ohio, USA. J. Appl. Microbiol. 4, 982-988. 